\title{
Indirect Bypass Procedures for Moyamoya Disease in Pediatric Patients
}

\section{Moyamoya Hastalı̆̆ı Olan Çocuklarda Indirekt Bypass Cerrahileri}

\author{
Tuncer TURHAN, Yusuf ERSAHIN \\ Ege University, Faculty of Medicine, Department of Neurosurgery, Izmir, Turkey
}

Correspondence address: TuncerTURHAN / E-mail: tuncert@gmail.com

\begin{abstract}
AIM: Many direct and indirect surgical intervention methods have been defined for the treatment of moyamoya disease. Indirect surgical procedures have been increasingly used. In this study, indirect surgical intervention methods especially used in combination with pial synangiosis were assessed together with other indirect methods.

MATERIAL and METHODS: 11 patients who were treated with an indirect bypass procedures at our clinic and followed for at least three years were retrospectively examined. 19 surgical interventions were performed for 18 patient hemispheres pertaining to these patients. 4 indirect surgical revascularization methods were used for three patient hemispheres. On the other hand, indirect procedures combined with pial synangiosis were applied in 11 operations. In addition, the "multiple burr-hole surgery" method was used in 4 four operations performed for two patients.

RESULTS: The clinical success rate was $66.6 \%$ for patients where the techniques were applied with pial synangiosis. No new ischemic or hemorrhagic attack was observed during the follow-up period in any of these patients in this series.

CONCLUSION: Pial synangiosis is a modification that Increases the success rate of indirect surgical methods. In addition, high success rates have been reported in recent publications related to multiple burr-hole surgery. This method is a candidate choice of surgical intervention for selected patients.
\end{abstract}

KEYWORDS: Moyamoya disease, Indirect bypass, Pediatric, Pial synangiosis

öz

AMAÇ: Özellikle çocuklarda görülen moyamoya hastalığının tedavisi için çok sayıda direkt ve indirekt cerrahi girişim yöntemi tanımlanmıştır. Bunlar arasında indirekt cerrahi prosedürler gittikçe artan bir şekilde kullanılmaktadır. Bu çalışmada, özellikle pial sinanjiozis ile kombine olarak kullanılan indirekt cerrahi girişim yöntemleri, diğer indirekt yöntemlerle birlikte değerlendirilmiştir.

YÖNTEM ve GEREÇ: Kliniğimizde indirekt bypass prosedürleri ile tedavi edilen ve en az 3 yıl izlenmiş olan 11 hasta retrospektif olarak incelenmiştir. Bu hastalara ait 18 hasta hemisfer için 19 cerrahi girişim yapılmıştır. 3 hasta hemisfer için 4 indirekt cerrahi revaskülarizasyon yöntemi uygulanmıştır. 11 operasyonda ise pial sinanjiozis ile kombine edilmiş indirekt prosedürler uygulanmıştır. Ayrıca iki hasta için yapılan 4 operasyonda da "multiple burr-hole surgery" prosedürü kullanılmıştır.

BULGULAR: Pial sinanjiozis yapılmış olan hastalar için klinik başarı oranı \%66,6 dır. Ayrıca bu serideki hastaların hiçbirisinde takip süresi içerisinde yeni iskemik veya hemorajik atak olmamıştır.

SONUÇ: Pial sianjiozis, indirekt cerrahi yöntemlerin başarı oranlarını arttıran bir modifikasyondur. Ayrıca multiple burr-hole surgery ile ilgili yeni yayınlarda yüksek başarı oranları rapor edilmiştir. Bu yöntem seçilmiş hastalarda ilk cerrahi girişim seçeneği olmaya adaydır.

ANAHTAR SÖZCÜKLER: Moyamoya hastalığı, İndirekt bypass, Çocukluk çağı, Pial sinanjiozis

\section{INTRODUCTION}

Moyamoya disease is a cerebrovascular occlusive disease characterized by bilateral stenosis of the internal carotid arteries. It was first described by Takeuchi (1957) and Suzuki (1966) in Japan where the moyamoya disease had the highest prevalence (28-31). Kuroda et al. reported that asymptomatic moyamoya disease could cause hemorrhagic or ischemic stroke (16). Direct and indirect surgical anastomosis procedures were described for treatment in the literature.
Direct surgical procedures mainly include superficial temporal artery (STA) to middle cerebral artery (MCA) bypass surgeries $(9,15)$. However, because of the surgical difficulties of these procedures for children, indirect procedures have appeared and been discussed in literature. These were encephalo-duroarteriosynangiosis (EDAS) (20), encephalo-duro-arteriomyosynangiosis (EDAMS) (14), encephalo-duro-myo-synangiosis (EDMS), encephalo-myosynangiosis (EMS) (10), omental transplantation (11) and multiple burr hole surgery (MBHS) $(3,13)$. Additionally, combinations of direct and indirect 
surgeries have also been used $(6,8,10,12,14)$. Touho et al. used direct bypass surgery after failed indirect anastomosis (32).

In clinical practice, we prefer indirect anastomosis procedures such as EDAS, EDMS, EDAMS, EMS with pial synangiosis and MBHS. Pial synangiosis (PS) was first described by Adelson and Scott in 1995 (1). In 2004, they published a patient series which included 126 moyamoya patients (27). All of the patients in this series were treated with indirect anastomosis combined with PS and full recovery was noted for 90 of them (71.4\%).

MBHS was first described in 1989 by Endo et al. (3). They placed frontal burr holes in five children with moyamoya disease and noted excellent results for all of them. In 1996, Kawaguchi et al. published a surgical series which included 10 adult patients (13). All the patients in this series were operated with MBHS only and high clinical and angiographical success rates were noted. In addition, Oliveira et al. (2009) reported successful MBHS results for 7 patients at pediatric age (24).

In this report, we focused on the surgical outcome of indirect procedures with PS. In addition, the $\mathrm{MBH}$ procedures were detailed with clinical examples.

\section{MATERIAL and METHODS}

\section{Patient characteristics}

Eleven patients ( 8 male and 3 female) or 18 sick hemispheres were operated between 1995 and 2007. In seven cases, moyamoya disease appeared bilaterally. The mean age of the patients at the time of first operation was 7.3 years ( 2 to 14 years). The disease appeared in hemorrhagic form in only one patient and no patient had a familial predisposition. Major symptoms were seizures in 6 and paresis in 8 patients. Diagnoses of all patients were verified with brain MRI (angiography, perfusion and diffusion images), single photon emission-computed tomography (SPECT) scans and Digital subtraction angiography. Frequent postoperative revisits and SPECT scans were used in the follow-up of patients. The mean follow-up time for this study was 8.8 years ( $3-14$ years). Table I summarizes the patient characteristics and outcome.

\section{Surgery}

Only indirect surgical procedures were used for the treatment of the sick hemispheres in this study group. The number of surgical procedures was 19 for 11 patients or 18 sick hemispheres. Seven EDAMS (5 of them combined

Table I: Surgical and Outcome Summary of the Study Group. Note that all the Patients in this Group had TIAs Initially. After Surgery, all the Patients Except Patient 8 and 9 had no TIA or New Neurological Deficits until the Present Time. Patients Grouped as "No Change" had the Same Constant Neurological Deficits

\begin{tabular}{|c|c|c|c|c|c|c|}
\hline Patient No & Age & Localization & $\begin{array}{l}\text { Surgical } \\
\text { Procedure }\end{array}$ & Symptoms & Clinical Outcome & $\begin{array}{c}\text { Follow-up Period } \\
\text { (years) }\end{array}$ \\
\hline 1 & 3 & Right ICA & EDAMS & Seizure+paresis & Recovery & 14 \\
\hline 2 & 14 & Left ICA & EDAMS & Seizure+paresis & Failure & 14 \\
\hline 2 & 14 & Left ICA & EDMS & Seizure+paresis & Recovery & 14 \\
\hline 3 & 12 & Right ICA & EMS & Paresis & No change & 11 \\
\hline 3 & 12 & Left ICA & EDAMS+PS & Paresis & No change & 11 \\
\hline 4 & 9 & Left ICA & EDAMS+PS & Paresis+aphasia & No change & 13 \\
\hline 4 & 9 & Right ICA & EDAMS+PS & Paresis & No change & 13 \\
\hline 5 & 4 & Left ICA & EDAS+PS & Paresis & Full recovery & 8 \\
\hline 5 & 4 & Right ICA & EDAS+PS & Paresis & Full recovery & 8 \\
\hline 6 & 13 & Left ICA & $\mathrm{EDAS}+\mathrm{PS}$ & Paresis & Full recovery & 7 \\
\hline 6 & 13 & Right ICA & EDAMS+PS & Paresis & Full recovery & 7 \\
\hline 7 & 4 & Left ICA & EDAS+PS & Seizure+paresis & Recovery & 8 \\
\hline 7 & 4 & Right ICA & EDAMS+PS & Seizure+paresis & Recovery & 8 \\
\hline 8 & 2 & Right ICA & EDAS+PS & Paresis & Exitus & - \\
\hline 9 & 7 & Left ICA & EDAS+PS & Seizure & Exitus & - \\
\hline 10 & 4 & Right ICA & MBHS & Seizure & Recovery & 3 \\
\hline 10 & 4 & Left ICA & MBHS & Seizure & Recovery & 3 \\
\hline 11 & 9 & Right ICA & MBHS & Seizure & Recovery & 3 \\
\hline 11 & 9 & Left ICA & MBHS & Seizure & Recovery & 3 \\
\hline
\end{tabular}


with PS), 6 EDAS (all combined with PS), 1 EDMS, 1 EMS and $4 \mathrm{MBH}$ procedures were used for the treatment. The total number of operations combined with PS was 11 . One patient was re-operated for the same hemisphere because of neovascularization failure. The EDMS procedure was applied for the hemisphere again in this patient who had undergone an EDAMS procedure in the first place. This is why the number of operations is one higher than the number of the sick hemispheres in this study.

The indirect surgical procedures were mainly used as described by Matsushima et al. in 1981 (20). The PS procedure was added to EDAMS and EDAS operations. PS is a kind of surgical modification that can be used with indirect arterial anastomosis procedures. In this procedure, the dissected superficial temporal artery (STA) is transposed and affixed to the brain surface, and the adventitial layer of the STA is sutured to the pia-mater with $10 / 0$ nylon suture. Surgical details were explained by Adelson and Scott (1).

MBHS surgery was also used for two patients bilaterally. In these surgical procedures, STAs of the patients were protected and multiple burr-holes were opened to the effected sides. In both patients, burr-holes were opened in the ACA (frontal bone) and MCA (parietal bone) areas. Seven burr-holes were opened for each hemisphere. Important key-point of the operations is the opening the dura and arachnoid, while widely preserving the meningeal arteries under magnification. Surgical details about MBHS surgery were noted by Kawaguchi et al (13).

Clinical results of the surgeries (outcome) for every sick hemisphere were classified as "exitus", "no change", "recovery" and "full recovery". There was no new neurological symptom
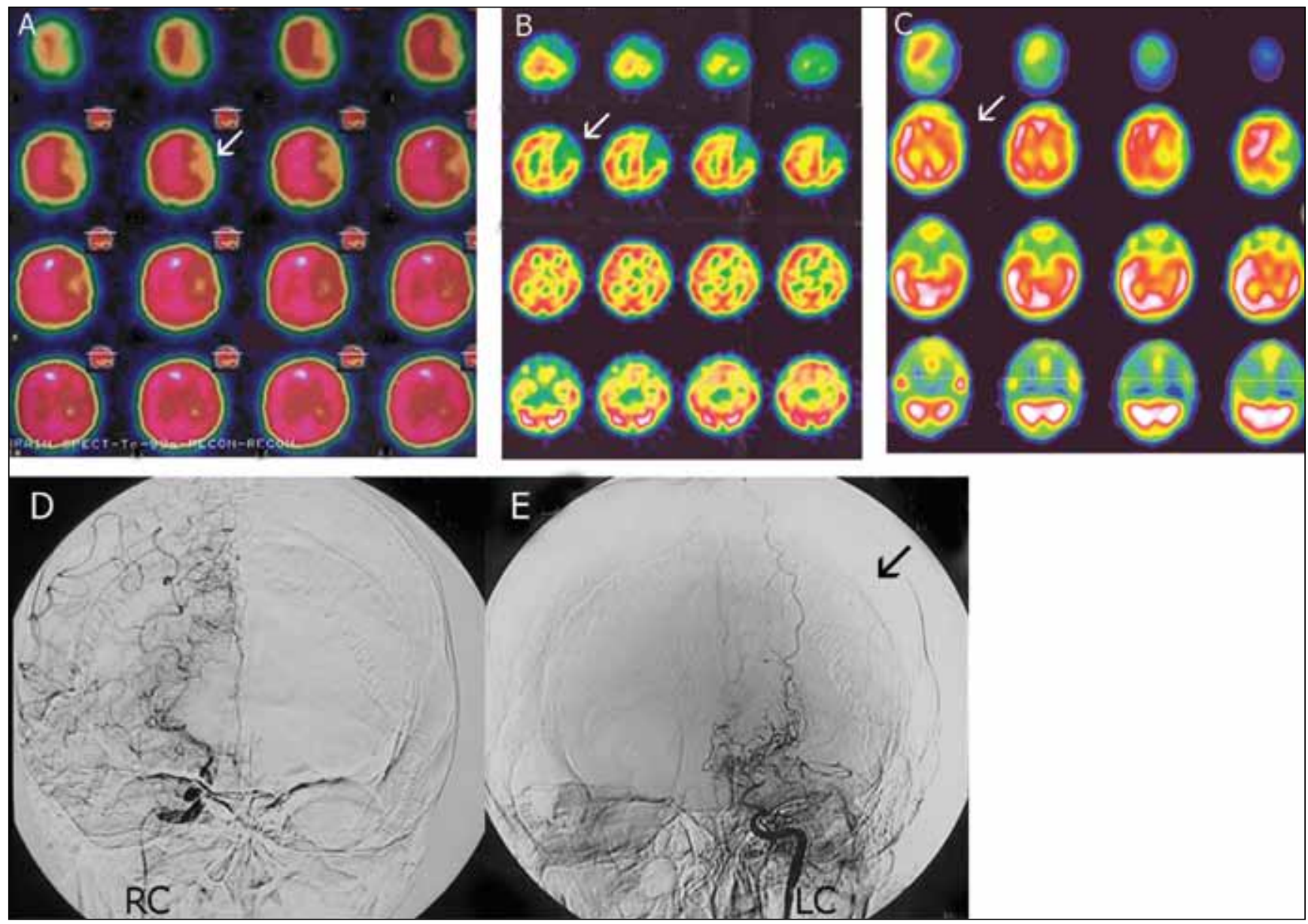

Figure 1: SPECT images of patient 6. A) preoperative Brain-SPECT images. Blood perfusion of the left parietal lobe is less than the other side. Brain-SPECT images one year B) and 4 years C) after the operation show perfusion of the left parietal lobe has improved, especially 4 years after the operation. In addition, no new ischemic area is seen in these images. Arrows show the low perfusion areas. Preoperative right D) and left E) carotid angiographies of the patient show bilateral occlusion of the carotid artery bifurcations. The black arrow shows the left parietal area. $\boldsymbol{R C}$ : Right carotid artery, LC: Left carotid artery. 
for the patients in this study group. In this classification, the "Recovery" term was used for the patients who preserved the initial neurological symptoms with clinical regression. Patients whose initial symptoms were completely treated were classified as "full recovery". Although there were different clinical outcome groups in this study, no new ischemic or hemorrhagic attack was observed for the patients during the follow-up periods. Therefore, patients were classified as "no change" only according to the initial constant neurological deficits. This term does not reflect surgical failure.

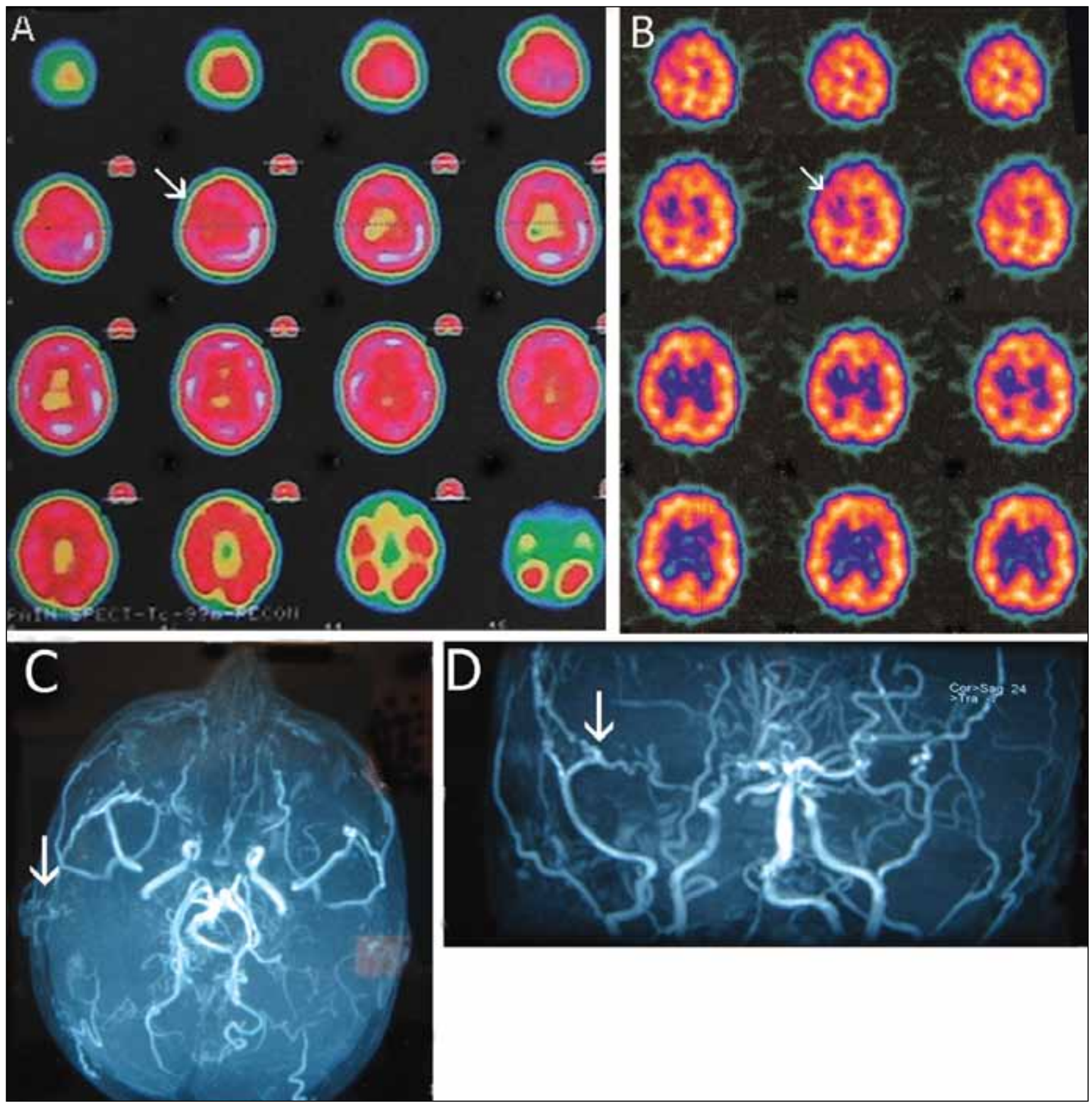

Figure 2: SPECT images of patient 11. In the preoperative A) and 2-year postoperative B) SPECT images, little arrows show the low perfusion area in the right hemisphere. Comparison of the two SPECT images shows no new ischemic area. Also, there is regression of the old low perfusion area after MBHS. In C and D, postoperative second-year MRI-angiographic images show neovascularization (big arrows) crossing the burr-holes, through the brain parenchyma. 


\section{RESULTS}

\section{Clinical Status}

Four indirect anastomosis surgeries without PS were done for 3 patients. One of the surgeries (for patient 2) was repeated for the same hemisphere because of the failure. There was no clinical change during the follow-up period of one patient with EMS surgery and recovery was noted for two patients with EDAMS and EMS procedures.

Eleven sick hemispheres were operated by indirect procedures with PS and 4 "full recoveries" (44.5\%), 2 "recoveries" (22.2\%) and 3 "no change" (33.3\%) were noted after the follow-up periods (mean 8.4 years). There were also 2 deaths in this group after the first hemispheric operations. We excluded these patients while calculating the outcome rates.

In the MBHS group, two patients were bilaterally operated for 4 sick hemispheres and the outcomes were classified as "recovery" for all.

Although there were different clinical outcome groups in this study, no new ischemic or hemorrhagic attack was observed in patients.

\section{Complications}

There were 2 deaths in the "indirect surgery combined with PS" group after the first hemispheric operations. Patient 8 (two years old) died 45 days after the surgery because of uncontrolled hyperglycemia attacks. Patient 9 (seven years old) who had well-known pulmonary hypertension before the operation died one hour after the surgery because of uncontrolled pulmonary hypertension and heart failure.

There was also a local incision problem for patient 4 in early follow-up periods. It was treated by using local and systemic antibiotics.

\section{Radiological Follow-up}

Early postoperative radiological images (CT and MRI) showed no additional brain infarct or hemorrhage for any patient. Patients were annually followed by MRI-angiographic images and SPECT studies. All the MRI-angiographic images showed neovascularization on surgical hemispheres in different degrees. SPECT studies also showed similar results. All the patient's surgical sites showed higher perfusion levels in different degrees or constant perfusions according to the preoperative SPECT images. No new ischemic or low perfusion area was seen in the SPECT's of the patients in this study.

\section{Illustrative case 1}

Patient 6 was a 13-year-old male. He was admitted to hospital because of the transient ischemic attacks (TIA) and bilateral paresis more serious on the right side. Digital subtraction angiographic images showed bilateral moyamoya disease and SPECT images showed low perfusion area on the left hemispheric region. Diagnosis was type-3 moyamoya disease and the patient underwent bilateral indirect anastomosis procedures (left EDAS and right EDAMS) combined with PS. One year after the surgery, full recovery was clinically noted at follow-up. Most importantly, the patient has been followed 7 years and there has been no new TIA or new neurological deficit. The SPECT image series of this patient also supported these findings. Figure $1 \mathrm{~A}-\mathrm{E}$ shows the radiological images of patient 6.

\section{Illustrative case 2}

Patient 11 was a nine-year-old boy admitted to the hospital with TIAs and secondary generalized epileptic seizures in the last two years. SPECT images showed a right hemispheric low perfusion area. After the angiographic examinations, diagnosis was bilateral type 2 moyamoya disease, and bilateral MBHS was performed. The follow-up period was 3 years for this patient and no epileptic seizure was noted with antiepileptic drugs. Also, there has been no new TIA attack clinically noted during follow-up and no new epileptic focus was seen in electroencephalographic examinations. Postoperative control SPECT images of the patient showed no new ischemic area and there was a great improvement of low perfusion zone after 2 years. The MRl-angiographic images also showed neovascularization in burr-hole areas. Figure $2 A-D$ shows the radiological images of this patient.

\section{DISCUSSION}

For moyamoya disease, the outcome is better with surgery as compared with the results of medical treatment although there is no controlled series to establish at this point $(2,5,26)$.

There are many surgical procedures suggested for moyamoya disease in the literature $(3,6-15,20)$. There have been various arguments about the effects of direct and indirect surgical procedures $(5,17-19,21,22)$. In some publications, the direct anastomosis procedure was found to result in the best postoperative collateral vessel formation and clinical improvement (19). However, the arteries may be too narrow for direct anastomosis, especially in children. Additionally, some patients have worsened after direct anastomosis because of the vasospasm of the cortical arteries (14,23,33). Furthermore, Matsushima et al. compared single indirect anastomosis with direct anastomosis surgeries in 1992 and reported that the single and multiple combined indirect nonanastomotic bypass procedures were safer than direct anastomosis $(4,19)$. Goda et al. also reported that good revascularization was seen after indirect procedures in most of the patients (4).

Because of these reasons, indirect bypass surgery is suggested for children in many articles which indicated that these procedures are more simple and less invasive than the direct anastomosis procedures $(14,17-20,25)$.

Pial synangiosis (PS) was first described by Adelson and Scott in 1995 to increase the anastomosis chance (1). In 2004, they published a patient series including 126 moyamoya patients (27). All the patients in this series were treated with indirect anastomosis combined with PS and full recovery was noted 
for 90 of them (71.4\%). In their study which included a great number of patients, the success rate of the indirect procedures was similar to direct bypass surgeries. After these reports, the indirect anastomosis procedures were preferred for children with moyamoya disease in the study. PS was also combined with these procedures as much as possible. Although there is no control group to compare, the success rate (recovery and full recovery patients) of the indirect anastomosis combined with PS was $66 \%$ in our study and is similar to Adelson and Scott's papers $(1,27)$. Other patients in this group are clinically classified as no change, but no TIA or new neurological deficit has been noted in the follow-up periods. In addition, SPECT images of the all patients in this group show stable or improvement perfusion areas for sick hemispheres.

On the other hand, MBHS was first described in 1989 by Endo et al (3). This procedure differs from indirect bypass surgeries like EDAS and EDAMS as the neovascularization occurs first from the dural arteries then from the STA (13). In 1996, Kawaguchi et al. published patient series operated with MBHS procedure (13). This series included 10 adult patients operated with MBHS and they explained that there was no mortality or morbidity, and no new neurological deficits or re-bleeding developed during the follow-up period (mean 34.7 months). In the present study, two moyamoya patients were operated with MBHS bilaterally. The outcome is similar to Kawaguchi et al's results. No new neurological deficits or new TIAs developed over two years of follow-up period. Furthermore, STA and dural arteries are still intact in these patients for any other surgical procedures if necessary. It gives patients a second direct or indirect operation chance.

Diversity of surgical interventions in clinical series presented in this study is improving in parallel with the developments in the history of indirect revascularization methods of mayomaya disease. Only the indirect revascularization methods were used in the initially operated patients. Subsequently, with the increasing popularity of pial synangiosis, indirect methods have been gradually modified with PS. Finally, studies reporting the success of MBHS and the low complication rates of this method indicate that this method could be the first choice for suitable patients $(13,24)$.

In conclusion, MBHS with/without indirect vascular bypass surgeries with PS should be the first choice of the moyamoya disease. PS may improve the success rate of indirect anastomosis surgery. On the other hand, MBHS is a simpler and safer procedure compared to both direct and indirect surgeries. We believe that prospective studies including larger patient series can make this procedure a strong alternative to other procedures.

\section{REFERENCES}

1. Adelson PD, Scott RM: Pial synangiosis for moyamoya syndrome in children. Pediatr Neurosurg 23:26-33, 1995

2. Choi J, Kim D, Kim E, Lee K: Natural history of moyamoya disease: Comparison of activity of daily living in surgery and non surgery groups. Clin Neurol Neurosurg 99 Suppl 2:11-18, 1997
3. Endo M, Kawano N, Miyaska Y, Yada K: Cranial burr hole for revascularization in moyamoya disease. J Neurosurg 71:180-185, 1989

4. Goda M, Isono M, Ishii K, Kamida T, Abe T, Kobayashi H: Long-term effects of indirect bypass surgery on collateral vessel formation in pediatric moyamoya disease. J Neurosurg 100:156-162, 2004

5. Golby A, Marks M, Thompson R, Steinberg G: Direct and combined revascularization in pediatric moyamoya disease. Neurosurgery 45:50-58, discussion 58-60, 1999

6. Houkin K, Kamiyama H, Takahashi A, Kuroda S, Abe H: Combined revascularization surgery for childhood moyamoya disease: STAMCA and encephalo-duro-arterio-myo-synangiosis. Childs Nerv Syst 13:24-29, 1997

7. Ishii K, Fujiki M, Kobayashi H: Invited article: surgical management of Moyamoya disease. Turk Neurosurg 18:107-113, 2008

8. Ishikawa T, Kamiyama H, Kuroda S, Yasuda H, Nakayama N, Takizawa K: Simultaneous superficial temporal artery to middle cerebral or anterior cerebral artery bypass with pan-synangiosis for Moyamoya disease covering both anterior and middle cerebral artery territories. Neurol Med Chir (Tokyo) 46:462-468, 2006

9. Karasawa J, Kikuchi H, Furuse S, Kawamura J, Sakaki T: Treatment of moyamoya disease with STA-MCA anastomosis. J Neurosurg 49:679-688, 1978

10. Karasawa J, Kikuchi H, Furuse S, Sakaki T, Yoshida Y: A surgical treatment of "moyamoya" disease "encephalo-myo synangiosis". Neurol Med Chir (Tokyo) 17:29-37, 1977

11. Karasawa J, Touho H, Ohnishi H, Miyamoto S, Kikuchi H: Cerebral revascularization using omental transplantation for childhood moyamoya disease. J Neurosurg 79:192-196, 1993

12. Karasawa J, Touho H, Ohnishi H, Miyamoto S, Kikuchi H: Longterm follow-up study after extracranial-intracranial bypass surgery for anterior circulation ischemia in childhood moyamoya disease. J Neurosurg 77:84-89, 1992

13. Kawaguchi T, Fujita S, Hosoda K, Shose $Y$, Hamano S, Iwakura M, et al: Multiple burr-hole operation for adult moyamoya disease. $J$ Neurosurg 84:468-476, 1996

14. Kinugasa K, Mandai S, Kamata I, Sugiu K, Ohmoto T: Surgical treatment of moyamoya disease: Operative technique for encephalo-duro-arterio-myo-synangiosis, its follow-up, clinical results, and angiograms. Neurosurgery 32:527-531, 1993

15. Kobayashi $H$, Hayashi $M$, Handa $Y$, Kabuto M, Noguchi $Y$, Aradachi $\mathrm{H}$ : EC-IC bypass for adult patients with moyamoya disease. Neurol Res 13:113-116, 1991

16. Kuroda S, Hashimoto N, Yoshimoto T, Iwasaki Y, Japan RCoMDi: Radiological findings, clinical course, and outcome in asymptomatic moyamoya disease: Results of multicenter survey in Japan. Stroke 38:1430-1435, 2007

17. Matsushima T, Fujiwara S, Nagata S, Fujii K, Fukui M, Hasuo K: Reoperation for moyamoya disease refractory to encephaloduro-arterio-synangiosis. Acta Neurochir (Wien) 107:129-132, 1990

18. Matsushima T, Fukui M, Kitamura K, Hasuo K, Kuwabara $Y$, Kurokawa T: Encephalo-duro-arterio-synangiosis in children with moyamoya disease. Acta Neurochir (Wien) 104:96-102, 1990

19. Matsushima T, Inoue T, Suzuki S, Fujii K, Fukui M, Hasuo K: Surgical treatment of moyamoya disease in pediatric patients-comparison between the results of indirect and direct revascularization procedures. Neurosurgery 31:401-405, 1992 
20. Matsushima Y, Fukai N, Tanaka K, Tsuruoka S, Inaba Y, Aoyagi M, et al: A new surgical treatment of moyamoya disease in children: $A$ preliminary report. Surg Neurol 15:313-320, 1981

21. Miyamoto S, Kikuchi H, Karasawa J, Nagata I, Yamazoe N, Akiyama $Y$ : Pitfalls in the surgical treatment of moyamoya disease. Operative techniques for refractory cases. J Neurosurg 68: 537-543, 1988

22. Nakagawa $Y$, Gotoh S, Shimoyama M, Ohtsuka K, Mabuchi S, Sawamura $Y$, et al: Reconstructive operation for moyamoya disease. Surgical indication for the hemorrhagic type, and preferable operative methods. Neurol Med Chir (Tokyo) 23:464470, 1983

23. Nakagawa $Y$, Shimoyama M, Kashiwaba T, Suzuki Y, Gotoh $S$, Miyasaka K, et al: Reconstructive operation of Moyamoya disease and its problems (author's transl). No Shinkei Geka 9:305-314, 1981

24. Oliveira R, Amato M, Simão G, Abud D, Avidago E, Specian C, et al: Effect of multiple cranial burr hole surgery on prevention of recurrent ischemic attacks in children with moyamoya disease. Neuropediatrics 40:260-264, 2009

25. Ross I, Shevell M, Montes J, Rosenblatt B, Watters G, Farmer J, et al: Encephaloduroarteriosynangiosis (EDAS) for the treatment of childhood moyamoya disease. Pediatr Neurol 10:199-204, 1994

26. Scott R: Surgery for moyamoya syndrome? Yes. Arch Neurol 58:128-129, 2001
27. Scott RM, Smith JL, Robertson RL, Madsen JR, Soriano SG, Rockoff MA: Long-term outcome in children with moyamoya syndrome after cranial revascularization by pial synangiosis. J Neurosurg 100:142-149, 2004

28. Suzuki J, Kodama N: Moyamoya disease--a review. Stroke 14: 104-109, 1983

29. Suzuki J, Takaku A: Cerebrovascular "moyamoya" disease. Disease showing abnormal net-like vessels in base of brain. Arch Neurol 20:288-299, 1969

30. Suzuki J, Takaku A, Asahi M: Evaluation of a group of disorders showing an abnormal vascular network at the base of the brain with a high incidence among the Japanese. 2. Follow-up studies by cerebral angiography. No To Shinkei 18:897-908, 1966

31. Takeuchi K, Shimizu K: Hypoplasia of the bilateral internal carotid arteries. Brain nerve:37-43, 1957

32. Touho H, Karasawa J, Ohnishi H, Yamada K, Shibamoto K: Surgical reconstruction of failed indirect anastomosis in childhood Moyamoya disease. Neurosurgery 32:935-940, 1993

33. Yonekawa $\mathrm{Y}$, Yasargil M: Brain vascularization by transplanted omentum: A possible treatment of cerebral ischemia. Neurosurgery 1:256-259, 1977 